\title{
A sovereign risk index for the Eurozone based on stochastic dominance
}

\author{
Elettra Agliardi \\ University of Bologna*
}

\author{
Mehmet Pinar \\ Edge Hill University ${ }^{\dagger}$
}

June 2014

\author{
Thanasis Stengos \\ University of Guelph ${ }^{\ddagger}$
}




\section{Introduction}

The widening and fluctuating behavior of sovereign risk premium differentials in the Eurozone, since the onset of the 2008-2010 financial crises, which jeopardized the creditworthiness of several Euro area countries, led a number of authors to question the determinants of sovereign differentials in the context of a monetary union and whether yield spreads are a good measure of sovereign risk default. ${ }^{1}$

At the same time, the recent crises showed the inadequacy of existing early warning signal (EWS) models that failed to ring alarm bells before the outburst of the crises. ${ }^{2}$

Understanding what has prompted recent changes in sovereign risk is particularly relevant for policymakers. Motivated by the current Eurozone sovereign debt crisis, our paper offers a further contribution to the existing literature on the determinants of sovereign risk and proposes a method to assess sovereign risk in the Eurozone. It is based on macroeconomic variables and employs a methodology that relies on consistent tests for stochastic dominance (SD hereafter) efficiency.

Most literature in the context of a monetary union has been dissecting a systemic risk factor, associated with shifts in international appetite, or "the effects of common macroeconomic shocks on economic fundamentals" (Ang and Longstaff, 2013, p. 493), and has discarded country-specific determinants (Eichengreen and Mody, 2000; Baek et al., 2005; Reinhart and Rogoff, 2009; Dieckmann and Planck, 2012). Spillovers effects and contagion (see e.g.,Kaminsky et al., 2003, Bekaert et al., 2011; Longstaff et al. 2011) have also been studied to analyze the common shock mechanism that is not related to country-specific fundamentals. However, other studies analyzing the recent financial crises led to controversial results. Barrios et al. (2009), looking at weekly data and using CDS spreads, find that the impact of domestic factors on yield spreads increased significantly during the crisis. They also suggest that because of the changes in public finances and the expected higher risk awareness of investors after the crisis, yield spreads raised at a higher level than in the pre-crisis period. Ang and Longstaff (2013) study the exposure of sovereigns to systemic and idiosyncratic shocks, comparing US states and countries inside the EU. They find that Greece had about three times the systemic risk of other vulnerable sovereigns, such as Portugal, Ireland, Italy, Spain and Belgium, which, in turn had roughly twice as much systemic risk as the remaining sovereigns in the EMU. Manasse and Zavalloni (2013) study CDS spreads inside the EU and explore possible regional contagion within the Eurozone. Their evidence supports the conclusion that country-specific fundamentals and structural fragilities matter for sovereign risk. Finally, Beirne and Fratzscher (2013), Beetsma et al. (2013), Kalotychou et al. (2013), and De Grauwe and Ji (2014) stress a role for sovereign's macroeconomic fundamentals and regional contagion during the European sovereign debt crisis.

Concerns about fiscal sustainability are significant for countries like Greece, Ireland, Italy, Portugal and Spain (see e.g., Gibson et al., 2012). At the same time, the use of public balance sheets to shore up

\footnotetext{
${ }^{1}$ The credit and banking crises, which anticipated the Eurozone sovereign debt crisis, culminated with the demise of Lehman Brothers in September 2008. Since then, doubts about the creditworthiness of individual European countries emerged. Fitch downgraded Ireland and Greece in Nov-Dec. 2009, but the apex was reached on 28 April 2010, when the intra-day interest rate for 2-year Greek government bond peaked at 38\%. After a series of downgradings and bailouts of Greece (Spring 2010), Ireland (Fall 2010), and Portugal (Spring 2011), the instability increased and both Italy and Spain were downgraded after summer 2011. Instability affected other EU countries, including Germany and France, and EU banks that held large porfolios of Eurozone sovereign debt. The Securities Markets Program was instituted by the ECB in May 2010. While initially only Greek debt was eligible, in summer 2010 the ECB started buying Irish and Portuguese debt and later Spanish and Italian. The overall size of the program reached $\$ 218$ billion in Dec. 2012.

${ }^{2}$ Among others, Davis and Karim (2008) applying macro EWS models, logit and binary recursive tree methodologies, found that for the US and UK these models failed to predict a crisis in 2007.
} 
national financial systems has also created a link between financial sector and public sector bailouts (see e.g., Sgherri and Zoli, 2009). In particular, each country has shown its own mix and strict interconnection between external, fiscal and financial imbalances, depending on specific circumstances (see e.g., Gibson et al., 2014; Honkapohja, 2014). Thus, there is a need of developing a measure to assess higher default risk for governments pursuing unsound fiscal policies, or economies exposed to weakness in the external trade sector. It would be also called for to make sure that the institutional system can address potential sources of instability in these dimensions.

In this paper we propose a construction of an aggregate index of sovereign risk in the Eurozone based on macroeconomic variables. Our focus on sovereign's macroeconomic variables is grounded on previous studies that rely on macro indicators as explanatory variables of a country vulnerability and/or contagion or spill-over effects from other countries. The methodology we employ is based on SD efficiency tests on multi-variate (multidimensional) comparisons of country panel data over various years. This methodology is new in the analysis of sovereign risk in the Eurozone, and leads to very promising results. It allows us to overcome a serious shortcoming of most empirical literature that performs a separate analysis of single-risk factors and thus ignores the association among the various determinants of sovereign risk ${ }^{3}$. It also seems to perform better than recent research developing a composite index with weights for indicators based on gaps from a long-term trend (see e.g., Borio and Drehmann, 2009), where the predictive ability drops considerably over short-term horizons.

SD efficiency tests are applied in Pinar et al. (2013) to construct an optimal human development index. A similar approach is also employed in Agliardi et al. (2012), where an optimal country risk index is constructed following SD analysis with differential component weights for emerging countries. Here we use the macroeconomic variables that are appropriate for the Eurozone and develop the worst-case scenario index for the Eurozone countries.

The intuition behind our method is that it provides an efficient index resulting from the least variable combination of risk factors that offers the maximum level of risk over time for each country or group of countries. Here relatively large data sets are available, so nonparametric analysis can let the data "speak for themselves". The optimality of the index refers to the fact that the weights given to each risk factors will make it stochastically dominate all other competitor indices, thus offering the maximum level of risk in Euro area countries for a given probability level and also the least volatile index over time among its set of competitors. In other words, rather than pair-wise SD comparisons of risk factors (see e.g., Barrett and Donald, 2003; Linton et al., 2005), we follow the Scaillet and Topaloglou (2010) SD efficiency methodology that allows for full diversification of weights to combine risk factors, which gives the maximum risk level for the Eurozone area. A further advantage is that by weighting each risk factor differently, we obtain optimal weights for the riskiest variables, which adds both theoretical and practical motivation to our index. It allows us to detect possible changes of the weights (i.e., change in riskiest combinations of factors) over time and/or for different groups of countries, in comparison to the arbitrarily weighted risk measures offered, for example, by rating institutions.

In summary, the main contribution of this paper is to derive an optimal sovereign risk index based on SD efficiency analysis. Additionally, our paper contributes to the current debates on the reliability of the rating assignment to countries by the rating agencies, the crises predictions by EWS models, and on the

\footnotetext{
${ }^{3}$ A broad empirical literature, based on regression analysis, studies debt crises as dependent variables, where, typically, a set of solvency indicators (such as the ratio of debt to GDP, GDP growth, the real exchange rate, liquidity indicators, the level of international reserves) are considered as independent variables. Other institutional and political variables, debt history, financing needs indicators and macroeconomic volatility may also be included (see e.g., Panizza et al., 2009).
} 
effectiveness of CDS spreads as good measures of sovereign risk default.

The remainder of the paper is as follows. Section 2 defines the main notation for SD. Section 3 presents the variables used for the analysis and their descriptive statistics. The main results are given in Section 4 where we provide overall and sub-group (fiscal and external trade) risk indices and rank the Eurozone countries for each respective risk index.

\section{$2 \quad$ Model Set-up}

In this section we present the test statistic for the SD efficiency of the sovereign risk index constructed from macroeconomic variables. Let $\left\{\boldsymbol{Y}_{t} ; t \in \mathbb{Z}\right\}$ denote a stochastic process with values in $\mathbb{R}^{n}$. The observations consist in a realization of $\left\{\boldsymbol{Y}_{t} ; t=1, \ldots, T\right\}$, and $n$ represents the different constituent components, i.e. macroeconomic variables, where $T$ is the total number of observations consisting of panel data set of countries, over a given period of time. We denote by $F(\boldsymbol{y})$, the continuous cdf of $\boldsymbol{Y}=\left(Y_{1}, \ldots, Y_{n}\right)^{\prime}$ at point $\boldsymbol{y}=$ $\left(y_{1}, \ldots, y_{n}\right)^{\prime}$. Let us take a composite index with equal weights (i.e., $\left.\boldsymbol{\tau}^{\prime} \boldsymbol{Y}\right)$ as a benchmark $(\boldsymbol{\tau}$ is the weighting vector of $\frac{1}{n}^{\prime} s$ ) to test the argument whether the equally-weighted index is SD efficient or a different set of weights would allocate relatively riskier macroeconomic environment. Consider an alternative weighting scheme $\boldsymbol{\lambda} \in \mathbb{L}$, where $\mathbb{L}:=\left\{\boldsymbol{\lambda} \in \mathbb{R}_{+}^{n}: \boldsymbol{e}^{\prime} \boldsymbol{\lambda}=1\right\}$ with $\boldsymbol{e}$ for a vector made of ones and denote by $G(z, \boldsymbol{\lambda} ; F)$ the cdf of the alternative composite index $\boldsymbol{\lambda}^{\prime} \boldsymbol{Y}$ at point $z$ given by $G(z, \boldsymbol{\lambda} ; F):=\int_{\mathbb{R}^{n}} \mathbb{I}\left\{\boldsymbol{\lambda}^{\prime} \boldsymbol{u} \leq z\right\} d F(\boldsymbol{u})$ where $\mathbb{I}$ denotes the indicator function $\mathbb{I}\left(\boldsymbol{\lambda}^{\prime} \boldsymbol{u} \leq z\right)$ and $z$ is a given risk level.

Define for $z \in \mathbb{R}$ :

$$
\begin{aligned}
& \mathcal{J}_{1}(z, \boldsymbol{\lambda} ; F):=G(z, \boldsymbol{\lambda} ; F), \\
& \mathcal{J}_{2}(z, \boldsymbol{\lambda} ; F):=\int_{-\infty}^{z} G(u, \boldsymbol{\lambda} ; F) d u=\int_{-\infty}^{z} \mathcal{J}_{1}(u, \boldsymbol{\lambda} ; F) d u,
\end{aligned}
$$

and so on. The empirical counterpart is obtained by integrating with respect to the empirical distribution $\hat{F}$ of $F$, that is, for the SD order of $j \geq 2$ :

$$
\mathcal{J}_{j}(z, \boldsymbol{\lambda} ; \hat{F})=\frac{1}{T} \sum_{t=1}^{T} \frac{1}{(j-1) !}\left(z-\boldsymbol{\lambda}^{\prime} \boldsymbol{Y}_{t}\right)_{+}^{j-1} .
$$

The hypotheses for testing whether the equally-weighted risk index, $\boldsymbol{\tau}^{\prime} \mathbf{Y}$, is relatively the worst-case scenario (i.e., the riskiest combination of the factors) is as follows:

$$
\begin{gathered}
H_{0}^{j}: \mathcal{J}_{j}(z, \boldsymbol{\tau} ; \hat{F}) \leq \mathcal{J}_{j}(z, \boldsymbol{\lambda} ; \hat{F}) \text { for all } z \in \mathbb{R} \text { and for all } \boldsymbol{\lambda} \in \mathbb{L}, \\
H_{1}^{j}: \mathcal{J}_{j}(z, \boldsymbol{\tau} ; \hat{F})>\mathcal{J}_{j}(z, \boldsymbol{\lambda} ; \hat{F}) \text { for some } z \in \mathbb{R} \text { or for some } \boldsymbol{\lambda} \in \mathbb{L} \text {. }
\end{gathered}
$$

Under the null hypothesis $H_{0}^{j}$, there is no composite risk index $\boldsymbol{\lambda}^{\prime} \boldsymbol{Y}$ constructed from the set of risk factors that dominates the benchmark equally-weighted risk index $\boldsymbol{\tau}^{\prime} \boldsymbol{Y}$ at SD order of $j$. In this case, $\mathcal{J}_{j}(z, \boldsymbol{\tau} ; F)$ is always lower than $\mathcal{J}_{j}(z, \boldsymbol{\lambda} ; F)$ for all possible risk indices constructed with any possible weighting scheme, $\boldsymbol{\lambda}$, at any risk level $z$. Under the alternative hypothesis $H_{1}^{j}$, an alternative risk index $\boldsymbol{\lambda}^{\prime} \boldsymbol{Y}$ exists, such that for some risk level $z, \mathcal{J}_{j}(z, \boldsymbol{\tau} ; F)$ is larger than $\mathcal{J}_{j}(z, \boldsymbol{\lambda} ; F)$. Thus, when $j=1$, the risk index that is obtained with equal weights, $\boldsymbol{\tau}^{\prime} \boldsymbol{Y}$, is stochastically not the riskiest case at the first-order, if and only if some other index with an alternative weighting scheme, $\boldsymbol{\lambda}^{\prime} \boldsymbol{Y}$, dominates it at some risk level $z$. Put in another way, the benchmark risk index $\boldsymbol{\tau}^{\prime} \boldsymbol{Y}$ is stochastically the worst-case scenario at the first-order, if and only if there is 
no alternative risk index $\boldsymbol{\lambda}^{\prime} \boldsymbol{Y}$ that dominates it at all levels of risk. SD efficiency tests can be specified at first- and second-order when $j=1$ and $j=2$, respectively (SD1 and SD2, hereafter).

In particular, we consider the weighted Kolmogorov-Smirnov type test statistic for testing whether the equally-weighted risk index is the worst-case scenario or not as follows:

$$
\hat{S}_{j}:=\sqrt{T} \frac{1}{T} \sup _{z, \boldsymbol{\lambda}}\left[\mathcal{J}_{j}(z, \boldsymbol{\tau} ; \hat{F})-\mathcal{J}_{j}(z, \boldsymbol{\lambda} ; \hat{F})\right],
$$

and a test based on the decision rule:

$$
\text { "reject } H_{0}^{j ", ~ i f ~} \hat{S}_{j}>c_{j},
$$

where $c_{j}$ is some (appropriate) critical value. In order to make the results more operational, we need to find an appropriate critical value $c_{j}$. Since the distribution of the test statistic depends on the underlying distribution, we rely on a block bootstrap method to simulate p-values (see Section 3 of Scaillet and Topaloglou, 2010 for the details). As the test statistic allows for full diversification of weights at all possible risk levels, we require a mathematical maximization method. We use a mixed integer program to obtain the test statistic for the first-order SD dominance, which maximizes the distance between the sum over all scenarios of two binary variables which represent $G(z, \boldsymbol{\tau} ; \hat{F})$ and $G(z, \boldsymbol{\lambda} ; \hat{F})$, respectively (the empirical cdf of risk indices with equal weights, $\boldsymbol{\tau}$, and an alternative weighting scheme, $\boldsymbol{\lambda}$, at a given risk level $z$ ), where binary values take a value of one when $z \geq \boldsymbol{\tau}^{\prime} \boldsymbol{Y}$ and $z \geq \boldsymbol{\lambda}^{\prime} \boldsymbol{Y}$ respectively, and zero otherwise. This formulation allows us to test the dominance of the risk index with equally-weighted index $(\boldsymbol{\tau})$ over any other potential risk index with an alternative weighting scheme $\boldsymbol{\lambda}$. If the first-order SDE does not hold, then the second-order dominance efficiency can be tested.

\section{Empirical Analysis}

\subsection{Data and Descriptive Statistics}

The data period in this analysis is 1 January 2006 until 31 December 2012. The sample contains quarterly data (between 2006 Q1 and 2012 Q4) and for the following Eurozone countries: Germany, France, Italy, Spain, Belgium, Greece, Portugal, Ireland, the Netherlands, Austria, Finland. Smaller countries within the EMU are not considered here, because of homogeneity of size or economic relevance.

To construct the index we employ the following macroeconomic variables: public debt/GDP - the higher public debt/GDP, the higher the risk of the country -; budget balance/GDP - the higher the positive value of the budget balance, the lower the risk of the country-; current account balance/GDP - the higher the positive value of the current account balance, the lower the risk of the country-; net international investment position (NIIP hereafter) as a percentage of GDP - the higher the net investment position, the lower the risk of the country-; unemployment rate - the higher the unemployment rate, the higher the risk of the country. Brief

data descriptions are presented in Table 1, where all data set is obtained from Eurostat. The descriptive statistics of all variables for the whole period and countries are in Table 2A.

Since all variables are measured in different units, we normalize each variable by linear rescaling technique to unit range, so that the normalized outcome of each variable is in the $0-1$ range. Then the normalized values of each variable are kept the same if that variable's higher values represent higher sovereign risk. If a variable affects a country's sovereign risk negatively, then we convert the normalized values of that variable, $\mathrm{X}$, into 1-X. Table 2B offers the descriptive statistics for normalized outcomes, where the higher normalized values represent higher risk for all variables. 
The chosen variables focus both on external and internal balances. The trade channel has often been associated with international spillovers. This channel may be particularly significant inside the EMU - since its foundation external trade and market integration are recognized as its cornerstones -, where intra-union exchanges are extensive. The country-specific macroeconomic variables considered here (i.e., the public debt/GDP ratio, the budget balance/GDP ratio, the current account balance as percentage of GDP and the unemployment rate) are usually recognized to affect the economic performance and the sovereign's ability to service its debt. They allow us to uncover whether cross-country variation in risk exposure can be explained by differences in economic fundamentals at the country level. Moreover, we can evaluate whether sovereign risk is affected by an increased sensibility to macroeconomics fundamentals. Indeed, investors may reconsider the importance of country-specific fundamentals which they previously overlooked (e.g., in Greece).

This set of variables allows us to sub-group them and disentangle the fiscal and the external trade effects for the Eurozone sovereign risk: we separate "fiscal" variables (public debt/GDP, budget balance/GDP) and "external trade" variables (current account/GDP, NIIP/GDP). The results of the empirical analysis are given in the next section.

\section{Results}

This section summarizes our findings of the test for SD1 efficiency of the overall risk index and of indices obtained considering sub-groups of variables. This sub-grouping is done both for robustness check and also to construct indices specific to fiscal and external trade risk effects within the Eurozone. The main findings are the following: the arbitrarily weighted risk indices are not effective to capture the worst-case scenario for sovereign risk; moreover, net international investment position/GDP and public debt/GDP are the main contributors to country risk; while there is a positive correlation between the rankings of the most vulnerable countries and the S\&P's ratings, there is weaker correlation for the other countries.

Table 3 summarizes the results for the overall macroeconomic risk index. The main contributor to the overall (macroeconomic risk) index is net international investment position/GDP with $70.7 \%$ weight, followed by public debt/GDP (16.83\%), current account/GDP (8.4\%), budget balance/GDP (3.76\%) and unemployment rate $(0.31 \%)$. Tables 4 and 5 show the results with different grouping of variables. Consistent with the overall macroeconomic risk findings, we find that public debt/GDP contributes the most for the fiscal risk index with a weight around 89\%, where the budget balance/GDP contributes with a weight around 11\% (Table 4). Similarly, for the external trade effects index, net international investment position/GDP contributes the most with a weight around $86 \%$, and the current account/GDP contribution is around $14 \%$ (Table 5). We also show the rankings of the countries, which are computed for the first, second, third and fourth quarters of 2012 for each respective index. Tables $6 \mathrm{~A}, 6 \mathrm{~B}$, and $6 \mathrm{C}$ represent the Eurozone country risk rankings for overall, fiscal, and external trade risks. Fig. 1 shows the over-time evolution of the overall risk index since 2006, while Figures 2 and 3 the over-time evolution of the two sub-indices (fiscal and external trade risk indices respectively).

From the analysis of the overall index, we can distinguish a first cluster consisting of the countries of the European periphery, i.e., Greece, Portugal, Ireland, Spain, and Italy, that experienced serious or moderate financial distress recently and whose governments had to implement severe policy measures. Among these countries, Greece registers the highest value of the risk outcome. We recall that the Greek sovereign debt crisis is commonly described as beginning in November 2009, when the new government of George Papandreou revised the 2009 Greek deficit from a previously estimated 5\% to an alarming 12.7\% of GDP. Besides, also the alternative starting date April 2010 is often considered, when S\&P's slashed Greece's sovereign debt 
rating to junk status. Figures 1, 2 and 3 describe the over-time worsening of risk for Greece, anticipating the downgrading that the rating agencies performed much later in time. A second cluster of countries consists of France, Austria and Finland, which all represented strong credits through the global crisis. A third cluster shows a similar pattern for the lowest risk countries, such as Germany, the Netherlands and Belgium. In particular, for these countries default risk barely changed during the crisis and, as remarked in Ang and Longstaff (2013), most of the risk was apparently due to changes in systemic risk.

This subdivision in clusters is very similar to Ang and Longstaff (2013) - with the exception of France -, although they used a completely different approach. France is ranked a little higher in our riskiness scale, also when we compare our rankings with the S\&P's ratings in $2012 .{ }^{4}$ Our index for France anticipates the downgrading that the big three credit raters performed much later in time (S\&P's and Moody's downgraded France's rating at the very end of 2012 and Fitch in July 2013), because of a heavier government debt load and poor prospects for growth. Thus, our index seems to act as an early warning index.

Finally, while there is a positive correlation between our rankings of the most vulnerable countries and the S\&P's ratings (Greece, Portugal, Ireland, Spain, Italy), the correlation for other countries is weaker (e.g., Belgium). It is well known that rating agencies, such as S\&P's, generally produce stable ratings even in the outbreak of a global economic and financial crisis and their ratings remained unchanged after excessively high or low spreads, in many cases; moreover, the three main agencies are more reluctant to upgrade when spreads are excessively low than downgrade when spreads are excessively high, showing an asymmetric trend. Our remarks above about the delay in the rating changes seem to confirm this view.

\subsection{Conclusion}

In this paper we propose a new method to assess sovereign risk index in Eurozone countries using an approach that relies on consistent tests for SD efficiency. The test statistics and the estimators are computed using mixed integer programming methods. We construct an overall index and indices specific to fiscal and external trade effects. We find that the arbitrarily weighted risk indices are not optimal and that net international investment position/GDP and public debt/GDP are the main contributors to country risk. The ranking of countries is performed together with an analysis of the over-time evolution of the overall index and two sub-indices (fiscal and external trade).

An extension of the current analysis is to employ forecasting models to obtain future projections of the macroeconomic variables for each Eurozone country. In a recent paper, Pinar et al. (2012) employ SD methodology to obtain the optimal forecast combination of forecasting models, an approach that could be applied to obtain forecasts of macroeconomic variables. Hence, using these forecasts and the weights obtained in this paper, one could estimate future risk levels of Eurozone countries. As such, our model could employ SD efficiency tests to analyze shorter span data to refine the forecast of future sovereign crises. Furthermore, one could periodically apply SDE methodology to the same group of Eurozone countries with the same set of variables to analyze whether there has been any change in the contribution of these variables to sovereign risk. Finally, our methodology could be fruitfully applied to other group of countries, and in particular to the other Euro countries that have been omitted in this analysis.

\footnotetext{
${ }^{4}$ The S\&P's ratings in 2012 are as follows: Greece $S D$; Portugal $B B /$ negative; Italy $B B B^{+} /$negative; Ireland $B B B^{+} /$negative; Spain $A$ /negative; Belgium $A A$ /negative; France $A A^{+} /$negative; Austria $A A^{+} /$negative; Finland $A A A$ /negative; The Netherlands $A A A$ /negative; Germany $A A A /$ stable.
} 


\section{References}

Agliardi, E., Agliardi, R., Pinar, M., Stengos, T., Topaloglou, N., 2012. A new country risk index for emerging markets: a stochastic dominance approach. Journal of Empirical Finance 19, 741-761.

Ang, A., Longstaff, F.A., 2013. Systemic sovereign credit risk: lessons from the US and Europe. Journal of Monetary Economics 60, 493-510.

Baek, I.-M., Bandopadhyaya, A., Du, C., 2005. Determinants of market-assessed sovereign risk: economic fundamentals or market risk appetite? Journal of International Money and Finance 24, 533-548.

Barrett, G.F., Donald, S.G., 2003. Consistent tests for stochastic dominance. Econometrica 71, 71-104.

Barrios, S., Iversen, P., Lewandowska, M., Setzer, R., 2009. Determinants of intra-euro area government bond spreads during the financial crisis. European economy Economic papers 388, European Commission, Directorate General Economic and Financial Affairs.

Beetsma, R., Giuliodori, M., De Jong, F. Widijanto, D. 2013, Spread the news: the impact of news on the European sovereign debt markets during the crisis. Journal of International Money and Finance 34, 83-101.

Beirne, J., Fratzscher, M., 2013. The pricing of sovereign risk and contagion during the European sovereign debt crisis. Journal of International Money and Finance 34, 60-82.

Bekaert, G., Ehrmann, M., Fratzscher, M., Mehl, A.J., 2011. Global crises and equity market contagion. NBER Working Paper No. 17121.

Borio, C., Drehmann, M., 2009. Assessing the risk of banking crises - revisited. BIS Quarterly Review (March), 29-46.

Davis, E.P., Karim, D., 2008. Comparing early warning systems for banking crises. Journal of Financial Stability 4, 89-120

De Grauwe, P., Ji, Y., 2014. How much fiscal discipline in a Monetary Union. Journal of Macroeconomics, forthcoming. http://dx.doi.org/10.1016/j.jmacro.2013.08.016.

Dieckmann, S., Plank, T., 2012. Default risk of advance economies: an empirical analysis of CDS during the financial crisis. Review of Finance 16, 903-934.

Eichengreen, B., Mody, A., 2000. What explains changing spreads on emerging market debt?, in: Edward, S. (Ed.), Capital flows and the emerging economies: theory, evidence and controversies. University of Chicago Press, Chicago, pp. 107-136.

Gibson, H.D., Hall, S.G., Tavlas, G.S., 2012. The Greek financial crisis: growing imbalances and sovereign spreads. Journal of International Money and Finance 31, 498-516.

Gibson, H.D., Hall, S.G., Tavlas, G.S., 2014. Fundamentally wrong: Market pricing of sovereigns and the Greek financial crisis. Journal of Macroeconomics, forthcoming. http://dx.doi.org/10.1016/j.jmacro.2013.08.006.

Honkapohja, S., 2014. The euro area crisis: A view from the north. Journal of Macroeconomics, forthcoming. http://dx.doi.org/10.1016/j.jmacro.2013.08.004

Kalotychou, E., Remolona, E., Wu, E., 2013. Intra-regional credit contagion and global systemic risk in international sovereign debt markets. Mimeo.

Kaminsky, G., Reinhart, G., Vegh, C., 2003. The unholy trinity of financial contagion. Journal of Economic Perspectives 17, 51-74.

Linton, O., Maasoumi, E., Whang, Y.-J., 2005. Consistent testing for stochastic dominance under general sampling schemes. Review of Economic Studies 72, 735-765.

Longstaff, F.A., Pan, J., Pedersen, L., Singleton, K., 2011. How sovereign is sovereign credit risk? American Economic Journal: Macroeconomics 3, 75-103. 
Manasse, P. , Zavalloni, L., 2013. Sovereign contagion in Europe: evidence from the CDS market. DSE-Unibo Working Paper No. 863.

Panizza, U., Sturzenegger, F., Zettelmeyer, J., 2009. The economics and law of sovereign debt and default. Journal of Economic Literature 47, 651-698.

Pinar, M., Stengos, T., Topaloglou, N., 2013. Measuring human development: a stochastic dominance approach. Journal of Economic Growth 18, 69-108.

Pinar, M., Stengos, T., Yazgan, M.E., 2012. Is there an optimal forecast combination? A stochastic dominance approach to forecast combination puzzle. Working Paper Series 17_12, The Rimini Centre for Economic Analysis.

Reinhart, C.M., Rogoff, K.S., 2009. This Time is Different: Eight Centuries of Financial Folly. Princeton University Press, Princeton.

Scaillet, O., Topaloglou, N., 2010. Testing for stochastic dominance efficiency. Journal of Business and Economic Statistics 28 (1), 169-180.

Sgherri, S., Zoli, E. 2009. Euro area sovereign risk during the crisis. IMF Working Paper No. 09/222. 
Table 1

Data Descriptions and Sources.

\begin{tabular}{ll}
\hline Macroeconomic fundamentals & Definitions \\
\hline Public debt/GDP & $\begin{array}{l}\text { The indicator is defined (in the Maastricht Treaty) as consolidated general } \\
\text { government gross debt at nominal value, outstanding at the end of the period. }\end{array}$ \\
\hline Public budget balance/GDP & $\begin{array}{l}\text { Public deficit/surplus (negative and positive values respectively) is defined in } \\
\text { the Maastricht Treaty as general government net borrowing/lending } \\
\text { according to the European System of Accounts (ESA95). }\end{array}$ \\
\hline Current Account Balance/GDP & $\begin{array}{l}\text { The current account balance (CAB) is the net lending/net borrowing of an } \\
\text { economy. It covers all transactions (other than those in financial items) that } \\
\text { involve economic values and occur between resident and non-resident units. }\end{array}$ \\
\hline $\begin{array}{l}\text { Net international investment } \\
\text { position (NIIP) /GDP }\end{array}$ & $\begin{array}{l}\text { Net international investment position (IIP) statistics record the financial } \\
\text { assets and liabilities position of a country vis-à-vis the rest of the world. }\end{array}$ \\
\hline Unemployment rate & $\begin{array}{l}\text { The unemployment rate is the number of unemployed persons as a percentage } \\
\text { of the labour force based on International Labour Office (ILO) definition. }\end{array}$ \\
\hline
\end{tabular}

Table 2A

Data and descriptive statistics (before normalization).

\begin{tabular}{lccccc}
\hline & Unemployment rate & Current Account & Budget Balance & Public debt & NIIP \\
\cline { 2 - 6 } Mean & 8.935 & -0.889 & -4.225 & 77.424 & -26.024 \\
Median & 7.900 & -0.900 & -3.230 & 71.600 & -17.600 \\
Std. Dev. & 4.781 & 6.659 & 6.513 & 30.271 & 51.943 \\
Minimum & 3.000 & -19.900 & -42.010 & 24.500 & -116.700 \\
Maximum & 26.100 & 11.900 & 11.740 & 170.300 & 67.600 \\
\hline
\end{tabular}

Table 2B

Data and descriptive statistics (normalized to unit range).

\begin{tabular}{lccccc}
\hline & Unemployment rate & Current Account & Budget Balance & Public debt & NIIP \\
\cline { 2 - 6 } Mean & 0.257 & 0.402 & 0.297 & 0.363 & 0.508 \\
Median & 0.212 & 0.403 & 0.279 & 0.323 & 0.462 \\
Std. Dev. & 0.207 & 0.209 & 0.121 & 0.208 & 0.282 \\
Minimum & 0.000 & 0.000 & 0.000 & 0.000 & 0.000 \\
Maximum & 1.000 & 1.000 & 1.000 & 1.000 & 1.000 \\
\hline
\end{tabular}

Table 3

Stochastic efficient weighting for macroeconomic fundamentals.

\begin{tabular}{|c|c|c|c|c|c|c|}
\hline $\begin{array}{l}\text { Number of } \\
\text { observations }\end{array}$ & $\begin{array}{l}\text { Number of dominating } \\
\text { weighting scheme }\end{array}$ & $\begin{array}{l}\text { Unemp. } \\
\text { rate }\end{array}$ & $\begin{array}{c}\text { CA } \\
\text { Balance }\end{array}$ & $\begin{array}{l}\text { Budget } \\
\text { Balance }\end{array}$ & Public debt & NIIP \\
\hline & & \multicolumn{5}{|c|}{ Average of dominating weighting schemes } \\
\hline 308 & 308 & 0.0031 & 0.0840 & 0.0376 & 0.1683 & 0.7070 \\
\hline
\end{tabular}

Table 4

Stochastic efficient weighting for fiscal variables.

\begin{tabular}{cccc}
\hline $\begin{array}{l}\text { Number of } \\
\text { observations }\end{array}$ & $\begin{array}{l}\text { Number of dominating } \\
\text { weighting scheme }\end{array}$ & Budget Balance & Public debt \\
\hline & & Average of dominating weighting schemes \\
\cline { 2 - 4 } 308 & 245 & 0.1144 & 0.8856 \\
\hline
\end{tabular}

Table 5

Stochastic efficient weighting for external trade variables.

\begin{tabular}{cccc}
\hline $\begin{array}{l}\text { Number of } \\
\text { observations }\end{array}$ & $\begin{array}{l}\text { Number of dominating } \\
\text { weighting scheme }\end{array}$ & CA Balance & NIIP \\
\hline 308 & 276 & Average of dominating weighting schemes \\
\cline { 2 - 4 } 3 & 276 & 0.1357 & 0.8643 \\
\hline
\end{tabular}


Table 6A

Rankings of Eurozone countries with respect to macroeconomic risk.

\begin{tabular}{lrlrlrlr}
\hline Country & $2012 \mathrm{Q} 1$ & Country & $2012 \mathrm{Q} 2$ & Country & $2012 \mathrm{Q} 3$ & Country & $2012 \mathrm{Q} 4$ \\
\hline Greece & 0.8445 & Greece & 0.8550 & Greece & 0.8562 & Greece & 0.9111 \\
Portugal & 0.8273 & Portugal & 0.8424 & Portugal & 0.8371 & Portugal & 0.8714 \\
Ireland & 0.7910 & Ireland & 0.7409 & Ireland & 0.7607 & Ireland & 0.8057 \\
Spain & 0.7183 & Spain & 0.7130 & Spain & 0.7087 & Spain & 0.7291 \\
Italy & 0.5176 & Italy & 0.5016 & Italy & 0.5051 & Italy & 0.5122 \\
France & 0.4591 & France & 0.4651 & France & 0.4625 & France & 0.4628 \\
Austria & 0.3477 & Austria & 0.3578 & Austria & 0.3493 & Austria & 0.3467 \\
Finland & 0.3044 & Finland & 0.2969 & Finland & 0.2859 & Finland & 0.2945 \\
Germany & 0.2126 & Germany & 0.2062 & Germany & 0.1993 & Germany & 0.1897 \\
Netherlands & 0.1523 & Netherlands & 0.1519 & Belgium & 0.1493 & Belgium & 0.1441 \\
Belgium & 0.1514 & Belgium & 0.1308 & Netherlands & 0.1297 & Netherlands & 0.1185 \\
\hline
\end{tabular}

Table 6B

Rankings of Eurozone countries with respect to fiscal risk.

\begin{tabular}{lrlrlrlr}
\hline Country & $2012 \mathrm{Q} 1$ & Country & $2012 \mathrm{Q} 2$ & Country & $2012 \mathrm{Q} 3$ & Country & $2012 \mathrm{Q} 4$ \\
\hline Greece & 0.7234 & Greece & 0.8011 & Greece & 0.8330 & Greece & 0.8423 \\
Italy & 0.6423 & Italy & 0.6450 & Italy & 0.6515 & Italy & 0.6507 \\
Portugal & 0.5751 & Portugal & 0.6090 & Portugal & 0.6163 & Portugal & 0.6432 \\
Ireland & 0.5515 & Ireland & 0.5603 & Ireland & 0.6059 & Ireland & 0.5951 \\
Belgium & 0.5113 & Belgium & 0.4968 & Belgium & 0.5131 & Belgium & 0.4848 \\
France & 0.4330 & France & 0.4365 & France & 0.4337 & France & 0.4278 \\
Germany & 0.3698 & Germany & 0.3736 & Germany & 0.3733 & Spain & 0.4233 \\
Austria & 0.3347 & Spain & 0.3628 & Spain & 0.3632 & Germany & 0.3746 \\
Spain & 0.3318 & Austria & 0.3381 & Austria & 0.3280 & Austria & 0.3185 \\
Netherlands & 0.2847 & Netherlands & 0.3046 & Netherlands & 0.3133 & Netherlands & 0.3129 \\
Finland & 0.1731 & Finland & 0.1875 & Finland & 0.1937 & Finland & 0.2215 \\
\hline
\end{tabular}

Table 6C

Rankings of Eurozone countries with respect to external trade risk.

\begin{tabular}{lrlrlrlr}
\hline Country & $2012 \mathrm{Q} 1$ & Country & $2012 \mathrm{Q} 2$ & Country & $2012 \mathrm{Q} 3$ & Country & $2012 \mathrm{Q} 4$ \\
\hline Portugal & 0.8856 & Portugal & 0.8946 & Portugal & 0.8827 & Greece & 0.9252 \\
Greece & 0.8773 & Greece & 0.8647 & Greece & 0.8458 & Portugal & 0.9202 \\
Ireland & 0.8432 & Spain & 0.7889 & Ireland & 0.7846 & Ireland & 0.8445 \\
Spain & 0.8092 & Ireland & 0.7715 & Spain & 0.7830 & Spain & 0.7896 \\
Italy & 0.4919 & France & 0.4763 & Italy & 0.4724 & Italy & 0.4803 \\
France & 0.4668 & Italy & 0.4699 & France & 0.4713 & France & 0.4744 \\
Austria & 0.3492 & Austria & 0.3655 & Austria & 0.3570 & Austria & 0.3556 \\
Finland & 0.3425 & Finland & 0.3316 & Finland & 0.3104 & Finland & 0.3135 \\
Germany & 0.1743 & Germany & 0.1670 & Germany & 0.1577 & Germany & 0.1442 \\
Netherlands & 0.1152 & Netherlands & 0.1113 & Netherlands & 0.0818 & Belgium & 0.0735 \\
Belgium & 0.0736 & Belgium & 0.0489 & Belgium & 0.0719 & Netherlands & 0.0680 \\
\hline
\end{tabular}




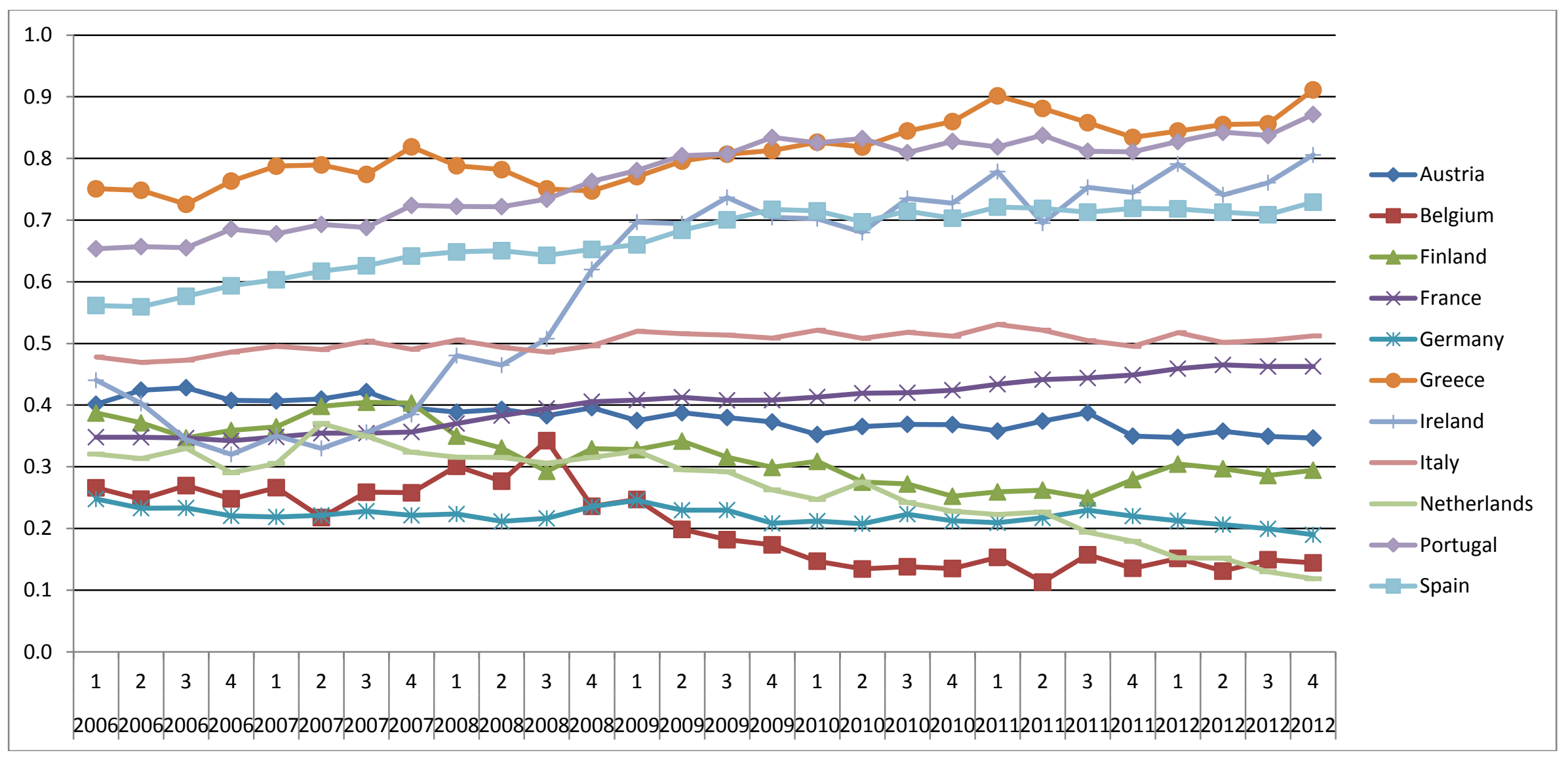

Fig. 1. Evolution of the macroeconomic risk over time 


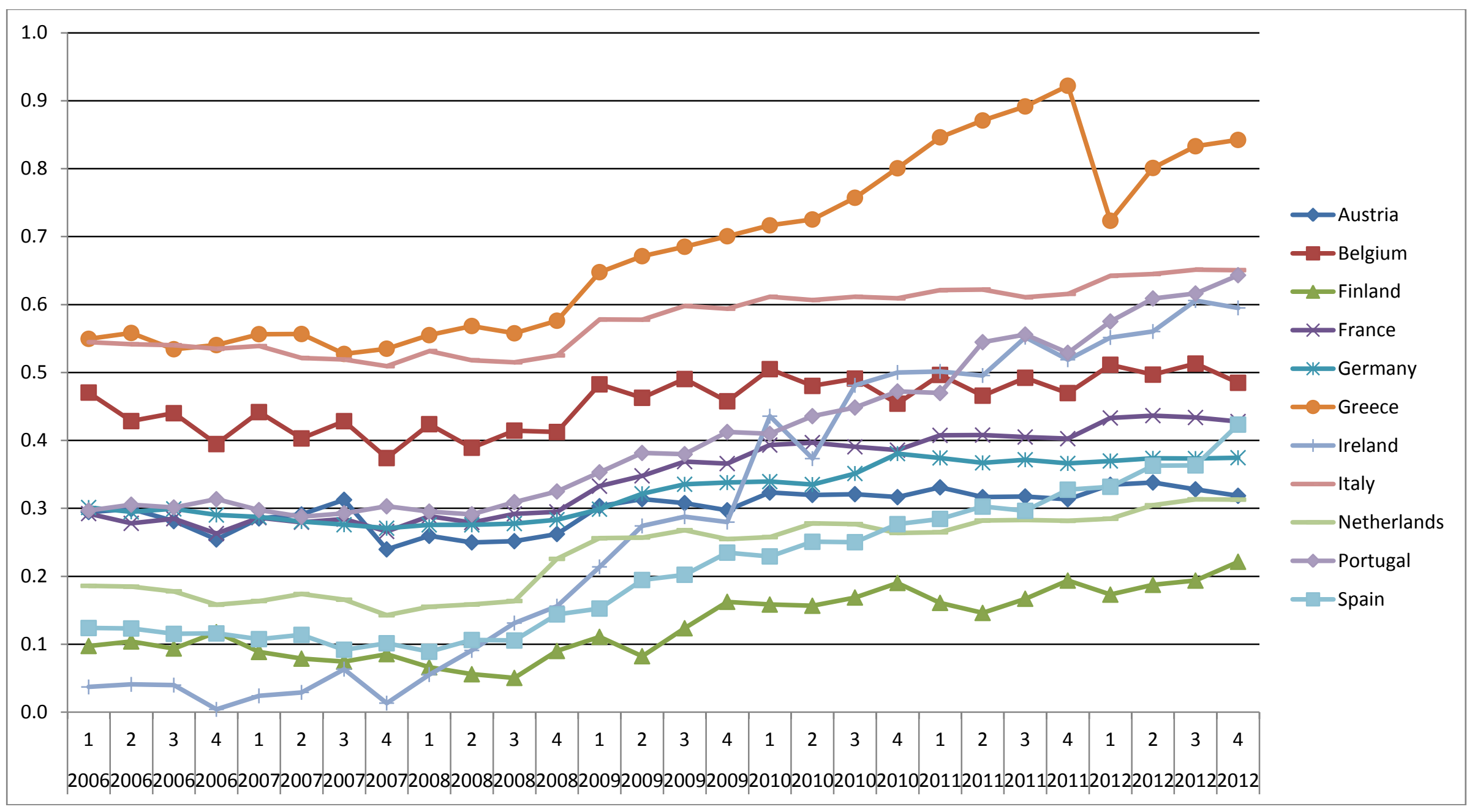

Fig. 2. Evolution of the fiscal risk over time 


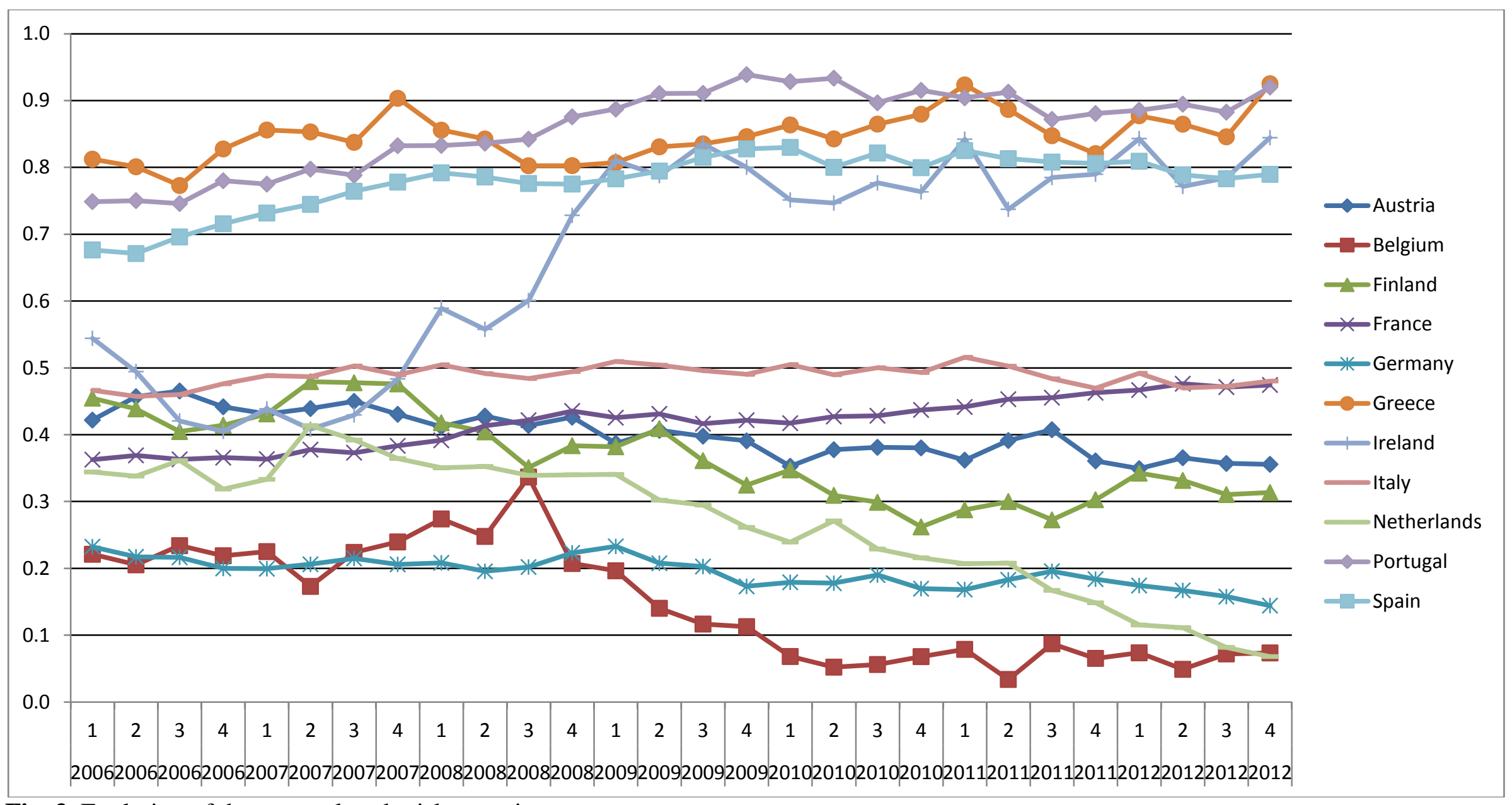

Fig. 3. Evolution of the external trade risk over time 